
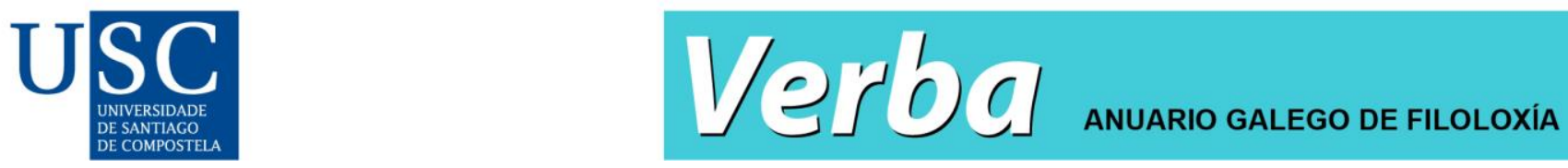

Verba: Anuario Galego de Filoloxía, 48, 2021. ISSN: 2174-4017

https://doi.org/10.15304/verba.48.6517

Artículos

\title{
Codificación sintáctica del aspecto en la derivación deverbal: el caso de los adjetivos en -nte y los nombres en -ncia
}

Syntactic encoding of aspect in deverbal derivation: the case of -nte adjectives and -ncia nominals in Spanish

\author{
María de los Ángeles Cano Cambronero', Matías Jaque Hidalgo² \\ 1Universidad Complutense de Madrid, España \\ 2Universidad de Chile, Chile
}

Recibido: 08/01/2020; Aceptado: 22/02/2020

\section{Resumen}

El objetivo de este trabajo es dar cuenta del impacto que tiene el aspecto léxico y sintáctico sobre dos procesos derivativos del español. Concretamente, ponemos el foco de atención sobre la derivación deverbal de los adjetivos en -nte y los nombres en -ncia, con el fin de mostrar que la diferente productividad que exhiben puede explicarse como una restricción sobre el dominio estructural de aplicación al que son sensibles ambos sufijos. Así, vamos a sostener a lo largo del trabajo que estos dos sufijos se muestran sensibles no solo al aspecto de la base verbal que seleccionan, sino también al nivel sintáctico-estructural en el que se codifica ese aspecto. En efecto, mientras - nte puede unirse a determinados predicados estativos derivados sintácticamente (o externos), -ncia está restringido al dominio del Sv, mostrando una mayor preferencia por los estados léxicos y en ningún caso pudiendo tomar como base lecturas aspectuales formadas por encima del Sv.

Palabras clave: Nominalizaciones, adjetivos deverbales, estatividad, aspecto externo, neoconstruccionismo

\begin{abstract}
The aim of this paper is to account for the impact that lexical and syntactic aspect has on two Spanish derivational processes. Specifically, we focus on the deverbal derivation of - nte adjectives and -ncia nominals, in order to show that the different productivity that they exhibit can be explained as a restriction on the structural domain of application to which both suffixes are sensitive. Thus, we are going to contend throughout this paper that these suffixes are sensitive not only to the aspect of the verbal source but also to the syntactico-structural level in which that aspect is encoded. Indeed, while -nte can be joined to certain syntactically (external) derived stative predicates, -ncia is restricted to the vP domain, showing a strong preference for lexical states and it never takes as verbal base or source aspectual readings formed above vP.
\end{abstract}

Keywords: Nominalizations, deverbal adjectives, stativity, external aspect, neo-constructionist approach 


\section{INTRODUCCIÓN}

En este trabajo abordamos el estudio y análisis de las restricciones de selección y las propiedades distribucionales exhibidas por dos tipos de formaciones léxicas del español: los adjetivos en -nte y los nombres en -ncia. Ambos sufijos se añaden mayormente a bases verbales (1), pero también a raíces latinas que no forman verbos en español (2):
a. abundarv > abunda-nte
b. abundarv > abunda-ncia
a. excele- $\quad>\quad$ excele-nte
b. excele- $\quad>\quad$ excele-ncia

El propio Diccionario de la Lengua Española $(D L E)$ da cuenta de la diferente etimología de este contraste. Así, si buscamos en el diccionario el adjetivo abundante, el resultado que obtenemos en el paréntesis etimológico es «De abundar y -nte» (s.v. abundar). En cambio, en el caso de excelente, el resultado es «Del latín excellens, -entis» (s.v. excelente). En este trabajo nos vamos a centrar en los ejemplos de (1), en la medida en que responden a un proceso sincrónico de formación de palabras en español. Así, de acuerdo con los ejemplos de (1), podría pensarse que estamos ante un caso de derivación en paralelo a partir de una base verbal que proporciona un significado conceptual básico, el cual se interpreta en términos de un adjetivo (verbo $+-n t e$ ) o de un nombre (verbo + -ncia). Sin embargo, hay ciertos contextos sintácticos y semánticos que distinguen entre ambos tipos de derivados:
a. El problema existe
b. un problema existe-nte
c. la existe-ncia del problema
a. Este objeto/producto \{corta / contamina / hidrata\}
b. un objeto/producto \{corta-nte / contamina-nte / hidrata-nte\}
c. la $\left\{{ }^{*}\right.$ corta-ncia / ${ }^{*}$ contamina-ncia / *hidrata-ncia $\}$ del objeto/producto

(4)

Según se muestra en (3), tanto - nte como - ncia pueden unirse a un verbo que denota un estado léxico (por ejemplo, el verbo existir) ${ }^{1}$. Sin embargo, parece que solamente el sufijo -nte puede unirse a un verbo de acción cuyo significado básico implica dinamicidad (por ejemplo, el verbo cortar). Justamente, los verbos que están en la base de los adjetivos en -nte de (4b) son verbos de acción que crucialmente adquieren un valor estativo en un contexto sintáctico concreto que implica una lectura disposicional del verbo (4a). En este sentido, un SN como un objeto cortante se refiere a un objeto 'que tiene la propiedad disposicional de cortar'. Esto es, si bien el significado básico del verbo cortar es dinámico: «Dividir algo o separar sus partes con algún instrumento 
cortante» (DEL, s.v. cortar); en el contexto sintáctico de (4a) el verbo adquiere una lectura disposicional, que es estativa. Por su parte, el sufijo -ncia parece que rechaza esta lectura verbal, mostrando una restricción de orden semántico y aspectual más fuerte, dado que solo puede unirse a verbos inherentemente estativos, quedando fuera aquellos verbos que admiten lecturas estativas obtenidas a partir del contexto sintáctico. Estas diferencias en las restricciones de selección de cada sufijo explican que -nte tenga un dominio de aplicación más amplio que -ncia, que sería, por tanto, un sufijo menos productivo. Estos datos nos llevan a proponer que -ncia se ve condicionado a operar en el dominio del Sv (es decir, el dominio sintáctico que determina el tipo de situación y la red argumental del predicado), incluyendo raíces, mientras que -nte puede actuar sobre el aspecto externo siempre que el núcleo específico esté marcado con valor disposicional. En consecuencia, aunque ambos sufijos seleccionan estados léxicos, solo -nte puede seleccionar lecturas verbales estativas obtenidas en proyecciones de aspecto externo. Esta propuesta aparece representada en la estructura de (5):

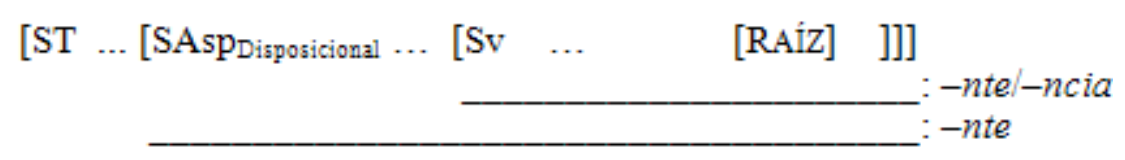

La estructura de (5) predice, tal y como vamos a argumentar en este trabajo, que - ncia da lugar a derivados no aceptables cuando se une a verbos dinámicos con lectura disposicional (*corta-ncia, *contamina-ncia, *hidrata-ncia). A su vez, sostenemos que esta aparente productividad más baja del sufijo -ncia se deriva del dominio estructural sobre el que el sufijo actúa o se aplica. En otras palabras, el número de bases verbales a las que -ncia se une es menor (cf. Pharies 2002) y la imposibilidad de derivados como los de (4c) puede predecirse a partir de la estructura. En este sentido, lo más apropiado sería decir que cada sufijo es "productivo" una vez que sus restricciones estructurales (aspectuales) son propiamente establecidas. Se hace preciso mencionar que nuestro análisis permite predecir la ausencia de nombres en -ncia formados sobre verbos dinámicos con lecturas disposicionales; en cambio, no pretendemos responder a la cuestión de por qué -nte no se combina con todos los verbos que pueden aparecer en lecturas disposicionales (este producto limpia bien > un producto *limpiante). Nuestra propuesta predice que limpiante puede ser una palabra posible, pero no existente. Dicho de otro modo, el verbo limpiar cumple a priori con los requisitos de selección que impone el sufijo, dado que es un verbo aspectualmente no delimitado o atélico (Cano 2013), de modo que no hay ninguna razón formal que impida la derivación del adjetivo en -nte. En este caso, podría afirmarse que se trata más bien de razones de orden léxicosemántico; es decir, la palabra no se ha creado porque no hay una necesidad comunicativa en la comunidad lingüística, muy posiblemente porque ya existe el adjetivo limpiador con ese significado disposicional. De hecho, hay otros verbos de significado dinámico que sí forman derivados en -nte y -dor bajo una lectura disposicional (contaminar > contaminante, contaminador), existiendo en este caso diferencias léxico-sintácticas o distribucionales entre ambos derivados (Cano 2013). Asimismo, nuestro trabajo tampoco se centra en aquellos adjetivos en -nte que se forman a partir de verbos de actividad sin necesidad de que muestren una lectura disposicional. Por ejemplo, balbucear > balbuceante (Juan balbuceó al responder / Juan respondió de forma balbuceante). Como acabamos de señalar, los adjetivos en -nte formados sobre verbos de actividad (atélicos) son 
esperables de acuerdo con la caracterización léxico-sintáctica del sufijo. Por su parte, la lectura disposicional está disponible para aquellos verbos que están subespecificados para la telicidad, tal y como explicamos en la sección 3.

El artículo se organiza como sigue: en la sección 2 presentamos el marco teórico usado en nuestro análisis: un enfoque neoconstruccionista (sintáctico) de la formación de palabras, haciendo referencia especialmente a las restricciones de orden semántico-aspectual y sintáctico que muestran los derivados con respecto a la base de derivación. En la sección 3 introducimos en detalle el estudio empírico, que nos muestra un caso particularmente sistemático en el que el paralelismo entre -nte y -ncia se rompe. En la sección 4 esbozamos una propuesta de análisis que dé cuenta de cómo este patrón empírico descrito puede explicarse en términos sintácticos. Finalmente, en la sección 5 mostramos el impacto que nuestra descripción y análisis tienen en la discusión general sobre la relación derivativa entre ambos sufijos, y crucialmente argumentamos que la propuesta de que los nombres en -ncia se forman sobre adjetivos en -nte no puede sostenerse (cf. Lang 1992; Santiago \& Bustos 1999; Pharies 2002).

\section{ACERCAMIENTO NEOCONSTRUCCIONISTA (SINTÁCTICO) A LAS FORMACIONES DEVERBALES}

En el $§ 1$ hemos mencionado que el dominio de aplicación de -nte y -ncia determina su distribución. Desde un punto de vista teórico, es relevante notar que nuestro estudio apoya la idea de que los sufijos son sensibles no solo al aspecto de la base verbal, sino también al nivel sintácticoestructural en el que ese aspecto se codifica. Tal y como demostramos empíricamente en el presente trabajo, el nivel estructural de estatividad (interna o externa) es crucial para el proceso derivativo, hasta el punto de que da cuenta de la ausencia de nombres en -ncia como *cortancia. Es importante mencionar que esta sensibilidad a las propiedades aspectuales de la base verbal es una propiedad compartida por otras formaciones deverbales en español y también en otras lenguas (cf. De Miguel 1996; Cornilescu 2001; Borer 2005b, 2013; Alexiadou 2011, 2012; Felíu 2012; Cano 2013; Jaque 2014; entre otros). Como ha sido estudiado en numerosos trabajos desde Grimshaw (1990), las restricciones de selección que imponen algunos sufijos sobre el verbo de la base van más allá de restricciones categoriales y de estructura argumental. Esto es, algunos procesos derivativos morfosintácticos están restringidos por propiedades aspectuales. De hecho, en ocasiones, el análisis tiene que ser más fino y la caracterización, por ejemplo, en términos de 'télico' y 'atélico', parece incluso no ser suficiente. Justamente, el estudio de los sufijos -nte y -ncia es un ejemplo que ilustra las restricciones sub-aspectuales que intervienen en la formación de algunos nombres y adjetivos deverbales.

Las nominalizaciones y los procesos de formación de derivados deverbales han ocupado el centro de la discusión lingüística durante las últimas décadas, convirtiéndose en el tema principal de estudio a la hora de ilustrar cómo funciona la interfaz léxico (morfología)-sintaxis. Un gran número de trabajos han abordado la Estructura Argumental y las propiedades verbales y aspectuales de las formaciones deverbales (cf. Marantz 1997; Borer 2005b, 2013; Alexiadou 2001, 2009, 2011; Alexiadou y Grimshaw 2008; Alexiadou et al. 2010; Alexiadou et al. 2011; Alexiadou \& Schäfer 2010; Marchis 2008; Harley 2009; Sichel 2010; Roy \& Soare 2012; y Fábregas 2010, 
2014; Fábregas \& Marín 2012; Oltra-Massuet 2010, 2014; Jaque \& Martín García 2012; Martín García 2011; Varela 2012; Cano 2013; Jaque 2014; para el español). Las cuestiones principales se han dirigido sobre: (i) cómo los procesos morfológicos tienen influencia en las propiedades sintácticas y semánticas de la formación léxica resultante; (ii) cuál es la naturaleza de la relación entre las propiedades de categorización sintáctica del verbo base y las de la formación deverbal resultante; (iii) cuál es la interacción entre el significado conceptual y la estructura sintáctica y cuál es la contribución de cada uno de estos niveles al significado global de la palabra. El interés de estos trabajos subyace a los diferentes aspectos lingüísticos que cubren, desde la morfología a la sintaxis, la semántica y la variación dialectal. La mayoría de estos trabajos se han enmarcado en un enfoque neoconstruccionista o sintáctico de la formación de palabras, que asume que la sintaxis es el único módulo generativo que hay en la gramática. De acuerdo con la visión más extrema, el concepto de palabra no tendría ninguna repercusión teórica significativa, en la medida en que los objetos complejos, bien sean palabras o sintagmas, se consideran el output del mismo sistema generativo, la sintaxis (Embick \& Noyer 2007). Una segunda afirmación - principalmente adoptada en el modelo neoconstruccionista exo-esquelético de Borer (2005a, 2005b, 2013), pero también en la Morfología Distribuida (véase Harley 2012) - es que la estructura sintáctico-funcional es el "lugar" donde reside la semántica composicional (en oposición a los valores conceptuales enciclopédicos). Así, los elementos atómicos como las raíces no contienen en absoluto información sintáctica relevante (siguiendo Borer 2005a, 2005b, 2013 y De Belder \& Van Craenenbroeck 2015), y no pueden contribuir a la expresión de la Estructura Eventiva y la Estructura Argumental, puesto que añaden solo matices conceptuales a la estructura funcional. Esta asunción teórica implica que toda la información categorial y lingüísticamente manipulable está codificada en la estructura sintáctico-funcional. Los enfoques neoconstruccionistas de la formación de palabras apuestan por que siempre que se identifique un patrón regular de forma-significado -esto es, que no se trate de un grupo de idiosincrasias léxicas, sino de un patrón productivo y generalizable- este tiene una explicación sintáctica.

En este sentido, la distribución de los adjetivos en -nte y de los nombres en -ncia es un claro ejemplo. De hecho, en este artículo defendemos que es posible ofrecer una explicación simple para este patrón de derivación si lo planteamos en términos sintácticos. Específicamente, en las siguientes secciones afirmamos que la lectura disposicional/genérica resulta accesible para los adjetivos en -nte, pero está bloqueada para los nombres en -ncia, dado el nivel aspectual (estructural) que ocupa este operador en la secuencia funcional (cf. Cinque 1999). Así, tal y como ha sido sugerido por Fábregas \& Marín (2012), en algunas lenguas -entre ellas el español- los afijos nominales deverbales tienden a aplicarse en el nivel del Sv (la primera fase en Chomsky 2001 o Ramchand 2008), de forma tal que aquellos contenidos aspectuales que se generan en capas funcionales externas no podrán ser heredados por un sustantivo que se derive mediante un afijo perteneciente a la clase en cuestión: -ción, -miento y, de modo crucial, -ncia. Si esta afirmación es cierta, entonces la ausencia de * cortancia es esperable, ya que el significado disposicional-genérico adquirido por el verbo base estaría más allá del alcance del afijo nominal; en contraste, el dominio de aplicación de -nte, como afijo adjetival, es más amplio, de modo que, al no restringirse al contenido aspectual exclusivamente codificado en el Sv podrá acoger valores generados en capas funcionales externas (en este caso, SAsp Disposicional; véase la sección 4 para mayores detalles). 


\section{LA RUPTURA EN EL PARALELISMO -NTE/-NCIA DADA POR LA LECTURA DISPOSICIONAL}

En español encontramos muchos pares como los ejemplificados en (6), que muestran un paralelismo entre -nte y-ncia:

(6) existente - existencia; abundante - abundancia; convergente - convergencia;

concordante - concordancia; ignorante - ignorancia

Considérense ahora los casos recogidos en la Tabla 1:

Tabla 1. Derivados en -nte y -ncia formados sobre verbos de cambio de estado

\begin{tabular}{|l|l|l|}
\hline \multicolumn{1}{|c|}{ verbo } & \multicolumn{1}{|c|}{- nte } & -ncia \\
\hline cortar & cortante & ${ }^{*}$ cortancia \\
\hline hidratar & hidratante & $*$ hidratancia \\
\hline contaminar & contaminante & ${ }^{*}$ contaminancia \\
\hline secar & secante & ${ }^{*}$ secancia \\
\hline disolver & disolvente & $*$ disolvencia \\
\hline diluir & diluyente & $*$ diluyencia \\
\hline edulcorar & edulcorante & $*$ edulcorancia \\
\hline desengrasar & desengrasante & $*$ desengrasancia \\
\hline fertilizar & fertilizante & $*$ fertilizancia \\
\hline exfoliar & exfoliante & $*$ exfoliancia \\
\hline
\end{tabular}

Como muestran los datos, para cada verbo de la primera columna hay un adjetivo en -nte, pero no es posible el nombre en -ncia. Cabe preguntarse qué propiedad tienen en común estos verbos y si esta propiedad podría guiarnos a la hora de explicar las restricciones aspectuales de cada sufijo. En una primera aproximación, parece que los verbos de la Tabla 1 pertenecen a la misma clase léxico-semántica: se trata de verbos de cambio de estado subespecificados para la (a)telicidad ${ }^{2}$. En otras palabras, estos verbos denotan eventos dinámicos que pueden interpretarse bien de forma télica o delimitada o bien de manera atélica o no delimitada, dependiendo del contexto sintáctico. Más específicamente, estos verbos parecen seleccionar un argumento interno que tiene la capacidad de intervenir en la naturaleza aspectual del evento, desencadenando una interpretación télica o atélica. Este tipo de argumento se corresponde con un argumento trayectoria 'path' en el 
modelo de Ramchand (2008). Cuando este argumento es definido (o cuantificado, en Borer 2005b), el evento recibe una interpretación delimitada, compatible con el modificador en x tiempo (e.g. Juan cortó el pastel en dos minutos). En cambio, si el argumento es indefinido (o no cuantificado), la interpretación resultante es no delimitada o atélica y, por tanto, compatible con el modificador durante $x$ tiempo (e.g. Juan cortó madera durante horas). Así, muy probablemente debido a esta subespecificación aspectual, los verbos de la Tabla 1 aceptan de forma natural una lectura estativa en el contexto sintáctico particular de (7):

\section{(7) Este cuchillo corta (bien).}

La predicación de (7) recibe en español una lectura disposicional-genérica. Esto es, el predicado adscribe una propiedad inherente a una entidad, propiedad que consiste en la realización potencial de un evento. En términos aspectuales, esta lectura es estativa, hasta el punto de que no se hace referencia a ningún evento concreto y simplemente se especifica la capacidad que tiene el cuchillo de cortar. En esta lectura, la "acción" expresada por el verbo es atemporal: ni ocurre ahora, ni tiene por qué haber ocurrido en el pasado - puede ser incluso que el cuchillo del que se predica la propiedad no se haya visto nunca envuelto en el proceso de cortar-, ni tiene por qué ocurrir en el futuro. Desde el punto de vista formal, la formación de este tipo de predicados es un proceso que convierte un verbo transitivo, que a menudo denota una realización, en un verbo que denota un estado. Esto es justamente lo que sucede en (7), donde hay una proposición estativa con lectura disposicional-genérica o no episódica. En (7) la ausencia de un argumento interno explícito está directamente ligada con la lectura disposicional. En ese caso, la variable eventiva del verbo estaría marcada por un operador genérico-disposicional (cf. Lekakou 2005; Alexiadou \& Schäfer 2010), como veremos más adelante en nuestra propuesta.

La naturaleza estativa del predicado ejemplificado en (7) puede sostenerse sobre la base de contextos gramaticales independientes. Por ejemplo, en algunas lenguas como el español y el inglés, las lecturas epistémicas orientadas al presente están disponibles solo con predicados estativos, quedando bloqueadas para los predicados eventivos (Soto 2008; Hallman 2010; Lundquist 2012; Jaque 2016; entre otros). Véanse a este respecto los ejemplos de (8):
a. Este cuchillo debe cortar bien.
b. Este cuchillo debe estar roto.
c. Juan debe cortar la carne.
d. El estudiante debe venir mañana.

El predicado de (8a) recibe una interpretación epistémica en la que probablemente el cuchillo tiene la capacidad o propiedad de cortar (bien), lectura análoga a la que recibe (8b): 'Es probable que el cuchillo esté roto', en este caso empleando un predicado de estado léxico. Sin embargo, este patrón no se sigue en (8c), donde el verbo cortar se usa con su valor eventivo dinámico y cuya lectura es similar a la de (8d), con un predicado claramente eventivo. En ambos casos, (8c) y (8d), se obtiene una lectura prospectiva-deóntica, mientras que la lectura epistémica orientada al 
presente queda bloqueada. En consecuencia, usando esta prueba podemos mostrar que las lecturas disposicionales se comportan de forma similar a los estados léxicos, incluso cuando estas se obtienen a partir de predicados dinámicos.

Ahora, en claro contraste con la disponibilidad de los adjetivos en -nte, ninguno de los verbos de la Tabla 1 da lugar a nombres en -ncia. Es importante hacer notar que la lectura estativa que admiten los verbos de la primera columna no puede por sí misma inhabilitar la aplicación del sufijo, ya que como mostraremos más adelante, -ncia no solo es compatible con estados, sino que parece exhibir una preferencia por ellos, como se aprecia en la lista de (9):

(9) existir > existe-ncia; tener > tene-ncia; permanecer > permane-ncia; distar > dista-ncia; creer > cree-ncia; abundar > abunda-ncia

Esta preferencia por los estados se ve claramente en aquellos casos en que, si el verbo que está en la base admite una interpretación eventiva además de una estativa, -ncia tiende a seleccionar esta última, tal y como puede observarse en (10):
a. Juan procede de familia italiana.
b. La procedencia italiana de Juan.
c. Juan procedió a resolver el asunto.
d. *La procede-ncia de Juan a resolver el asunto.

El verbo proceder admite una interpretación asociada a un significado estativo (10a) y a uno eventivo (10c). Como se ve en (10d), la derivación con -ncia sobre la lectura eventiva no está disponible en el léxico español. Finalmente, en algunos casos que a priori escaparían a esta pauta porque -ncia estaría escogiendo bases eventivas, el significado del derivado se corresponde con la lectura de objeto o de resultado, las cuales tienen con frecuencia un significado altamente idiosincrásico. En (11) tenemos algunos ejemplos:
(11)
a. ganar
ganancia
b. competir
competencia
c. obedecer
obediencia
d. presidir
presidencia

Pese a todo, es posible encontrar algunos nombres en -ncia que se forman sobre una base verbal eventiva. Por ejemplo, convergencia < converger, en contextos como la convergencia de ambos países tuvo lugar en la última reunión. Pero aun en estos casos hay una tendencia fuerte a preferir la lectura estativa (e.g. tenemos que dar pasos hacia la convergencia de ambos países). El punto importante es que, incluso si -ncia acepta predicados eventivos, en ningún caso rechaza estados, 
de modo que en principio tendría que ser compatible aspectualmente con los verbos de la Tabla 1. Naturalmente, la tendencia atestiguada a la hora de seleccionar estados léxicos hace más destacable la ausencia de esos nombres en -ncia.

A la luz de esta evidencia empírica, la pregunta que surge es ¿por qué -ncia no puede tomar las bases verbales de la Tabla 1 si, tal y como se ha mostrado en (7) y (8), tales verbos admiten una lectura estativa? En este punto hay que notar que existe una importante diferencia entre la ambigüedad aspectual que muestran los verbos de la Tabla 1 y otros verbos como proceder. El caso de este último puede verse como un ejemplo de polisemia léxica. De hecho, no hay forma de predecir, excepto por medio de procesos conceptuales tales como relaciones metafóricas, cuándo un verbo con significado eventivo como proceder tendrá también una variante estativa. Además, en los casos en que se dan las dos lecturas posibles, su significado enciclopédico es completamente independiente. Por su parte, los verbos de la Tabla 1 son diferentes en la medida en que disponen sistemáticamente de una lectura disposicional-genérica, sin desarrollar ningún significado conceptual especial más allá de la lectura disposicional. En consecuencia, la polisemia de verbos como proceder necesita ser almacenada en el léxico, mientras que la polisemia del verbo cortar es susceptible de tratamiento sintáctico. Como argumentamos en las siguientes secciones, la estatividad "léxica" es la que se encuentra generalmente disponible para -ncia, mientras que los procesos sintácticos implicados en la lectura disposicional tienen el efecto indirecto de impedir la aplicación de este sufijo nominal.

\section{HACIA UNA EXPLICACIÓN SINTÁCTICA}

\section{1. -nte vs. -ncia o aspecto externo vs. aspecto interno}

En este subapartado proponemos que el problema planteado por la ausencia sistemática de los nombres en -ncia en el paradigma de la Tabla 1 puede ser explicado introduciendo una diferencia entre estatividad interna o léxica y estatividad externa o derivada. Estos niveles de estatividad se correlacionan respectivamente con la distinción aspectual asumida desde Verkuyl (1993) entre aspecto interno o léxico y aspecto externo o gramatical, tal y como se detalla en (12):

$$
\left[\mathrm{ST} \ldots\left[\begin{array}{llll}
\mathrm{SAsp} & \ldots & {[\mathrm{Sv}} & \ldots
\end{array}\right]\right]
$$

Aspecto externo

Aspecto interno

El aspecto interno o léxico se corresponde con el dominio del Sv. En los enfoques sintácticos del significado verbal, este incluye las proyecciones funcionales de la primera fase sintáctica (firstphase syntax en Chomsky 2001 o Ramchand 2008). Esta primera derivación sintáctica determina las características temporales internas del predicado y proporciona posiciones argumentales jerarquizadas para el ensamble de sus participantes (los papeles temáticos). En otras palabras, el aspecto interno es el dominio de la Estructura Eventiva (Aktionsart) y de la Estructura Argumental. Tomando como referencia (12), los verbos que denotan estados léxicos, como los verbos 
existenciales (e.g. abundar), están estructuralmente definidos en el dominio del aspecto interno: su significado básico hace referencia a una relación entre entidades y propiedades. Ahora bien, es sabido que el aspecto léxico de un predicado puede verse modificado por factores contextuales, tales como la presencia de operadores aspectuales, modificadores adverbiales o perífrasis verbales. En este sentido, el aspecto externo involucra la aplicación de una función semántica -expresada por una proyección sintáctico-funcional por encima de Sv-sobre los eventos léxicos o los estados ${ }^{3}$.

En $\S 3$ hemos mostrado que los verbos del tipo cortar tienen un significado dinámico inherente o no-derivado, como recoge el $D L E$. En cambio, la lectura disposicional que exhiben aparece como una lectura derivada que se aplica en ciertos contextos gramaticales, preservándose el significado enciclopédico básico. Esto es, cortar, en la oración este cuchillo corta, mantiene su significado de 'Dividir algo o separar sus partes', pero es "visto" desde un punto de vista potencial: el evento no está teniendo lugar, pero podría, por lo que respecta a las propiedades del objeto. Por tanto, podemos suponer que la lectura disposicional pertenece al dominio del aspecto externo antes que al interno. La cuestión entonces es cuál es la posición sintáctica específica reservada para la lectura disposicional. Si tomamos como referencia la jerarquía de Cinque (1999: 99), podemos localizarlo por encima de Sv y por debajo de Aspecto Habitual ya que, como afirma el autor, este último debe mantenerse como una categoría aspectual distinguida de la lectura genérica (cf. Dahl 1985: 97; Fernández Leborans \& Sánchez 2015). Mientras que el término disposicional está ausente en la propuesta de Cinque, el concepto que implica puede asimilarse al de aspecto genérico ${ }^{4}$. Nótese que los adverbios que marcan la habitualidad (habitualmente, a menudo, etc.) son incompatibles con oraciones genéricas (ejemplos tomados de Cinque 1999: 99):
a. *John is usually a man.
'Juan es habitualmente un hombre'
b. *Whales are usually mammals.
'Las ballenas son habitualmente mamíferos'

De acuerdo con Cinque, el aspecto genérico cuenta como un valor defectivo para el aspecto progresivo o episódico. En palabras del autor, «las oraciones genéricas incluyen un operador genérico en la posición de Especificador del núcleo aspectual, el cual puede también llevar (como su valor marcado) un operador episódico [...], o progresivo» (traducción nuestra). Así, cuando un predicado se concibe como un evento que está teniendo lugar, se activa el valor marcado de ese núcleo aspectual, mientras que permanece inactivo si solo nos referimos a la realización potencial del evento. Adicionalmente, el aspecto genérico carece de presuposición existencial, al contrario, otra vez, de los predicados habituales (cf. Scheiner 2002; Carlson 2012). Esto es, mientras que una oración habitual implica que el evento ha tenido lugar, es decir, ha ocurrido al menos una vez, las oraciones genéricas pueden ser verdaderas incluso si el evento que nombran nunca ha tenido lugar. Como observa Cinque, cuando decimos «este coche corre a 280 kilómetros por hora», la oración puede ser adecuada incluso si el coche nunca ha estado en la carretera. Estos ejemplos nos llevan a la conclusión de que el aspecto habitual es semánticamente más complejo, al implicar la elaboración de una propiedad derivada de un evento que ocurre con una determinada frecuencia. Por otro lado, el aspecto genérico se corresponde con la no-activación del valor episódico, y se ve 
favorecido por algunos contextos gramaticales, como la ausencia del argumento interno. De acuerdo con la propuesta de Cinque, esta diferencia en la complejidad semántica se correlaciona con una diferencia en la jerarquía sintáctica. Así, una versión reducida de la secuencia funcional adoptada aquí es la de (14). De este modo, lo que descriptivamente hemos etiquetado más arriba como 'lectura disposicional' se entendería aquí como el valor defectivo del nodo aspectual episódico. En este marco, el lugar más bajo que el aspecto disposicional/genérico ocupa respecto del habitual cobra sentido, toda vez que el valor progresivo (la opción marcada del episódico) se asume, a partir de motivación empírica independiente, como una capa más interna.

$$
[\text { Asp Habitual } \quad[\text { Asp }[+/- \text {-Episódico }] \quad[\text { Sv...] }]]
$$

Tomando el esquema de (14) en consideración, la generalización empírica mostrada en los apartados anteriores puede reformularse ahora como un problema de sensibilidad a dominios aspectuales diferentes. Así, tanto -nte como -ncia pueden seleccionar estados, pero si -ncia está restringido al dominio del aspecto interno (esto es, al dominio del Sv), y -nte puede operar en ambos niveles aspectuales (interno y externo), los datos de la Tabla 1 son esperables. En otras palabras, si el sufijo -ncia está condicionado a operar dentro del dominio del aspecto interno, solo puede unirse a verbos que denotan estados léxicos. Finalmente, para el aspecto habitual, -nte, siendo más libre que -ncia, está sujeto también a restricciones estructurales. Por lo tanto, aunque los verbos con lectura habitual son atélicos y estativos, esa lectura queda fuera del alcance de -nte, como se ve en (15):
a. Juan come siempre verduras
$>\quad$ *Juan es comie-nte de verduras
b. Juan lee siempre el diario
$>\quad$ *Juan es leye-nte del diario
c. Juan trabaja en casa
$>\quad$ *Juan es trabaja-nte en casa

Los datos de (15) llevan a pensar que -nte, a pesar de mostrarse menos restrictivo que -ncia a la hora de formar derivados, solo es compatible con aquellas lecturas verbales que quedan definidas dentro del alcance estructural sobre el que puede operar, dada su subespecificación de rasgos de selección. En definitiva, estos sufijos operan en diferentes niveles estructurales, como se resume en la Tabla 2:

Tabla 2. Niveles estructurales para -nte y -ncia

\begin{tabular}{|l|l|l|}
\hline & - nte & -ncia \\
\hline Asp Habitual & ${ }^{*}$ comiente $(<$ comerv) & ${ }^{*}$ comiencia $(<$ comerv $)$ \\
\hline Asp [-Episodico] (Disposicional) & cortante $(<$ cortarv) & ${ }^{*}$ cortancia $(<$ cortarv) \\
\hline $\mathrm{Sv}$ & distante $(<$ distarv) & distancia $(<$ distarv) \\
\hline
\end{tabular}


Otra evidencia empírica que apoya la Tabla 2 es la existencia de ciertos adjetivos en -nte que se aplican a verbos télicos de cambio de estado o lugar, los cuales también carecen del correspondiente nombre en -ncia:
(16)
a. salir
$>\quad$ saliente $/ *^{*}$ saliencia
b. entrar
$>$
entrante /*entrancia

De acuerdo con Cano (2013), si consideramos que -nte se une a bases verbales de naturaleza atélica, estos derivados, que claramente denotan eventos puntuales (logros), son en una primera aproximación no esperables. Sin embargo, Cano argumenta que estos adjetivos codifican el estado previo al evento. Así, pueden parafrasearse con la perífrasis temporo-aspectual ir a + infinitivo o estar a punto de + infinitivo, como se puede observar en los siguientes ejemplos:

(17) a. El presidente saliente

i. El presidente que va a salir

ii ??El presidente que ha salido (lectura episódica)

(18) b. El presidente entrante

i. El presidente que va a entrar

ii. ??El presidente que ha entrado (lectura episódica) ${ }^{5}$

Aunque estos ejemplos no se corresponden con un patrón productivo, pueden considerarse parecidos a los que hemos explicado para el paradigma de verbos que admiten lectura disposicional. Si -nte está subespecificado para seleccionar una lectura atélica, verbos como entrar o salir -con un Aktionsart inherentemente télico- solo pueden satisfacer este requisito bajo una lectura aspectual externa al Sv, la cual se corresponde en este caso con un estado preparatorio al evento. Nuevamente, hay en principio una incompatibilidad aspectual con -ncia. En efecto, si usamos la prueba basada en las lecturas epistémicas orientadas al presente (véase 8c, d), construcciones como estar a punto de o la perífrasis ir a + infinitivo encajan con estados léxicos. Por ejemplo, la oración Juan debe estar a punto de comer el pastel tiene una lectura epistémica disponible. Por otra parte, el futuro simple del español admite también un valor epistémico si se aplica a predicados estativos: e.g. Juan estará en casa puede interpretarse como 'probablemente él esté en casa' (cf. Soto 2008; Jaque 2016). En este caso, lo relevante es que la perífrasis ir a + infinitivo acepta el morfema de futuro sobre el verbo auxiliar dando lugar a una aserción modal: e.g. Juan irá a venir ¿no?, con el sentido de 'probablemente Juan va a venir' (cf. Soto 2008). En definitiva, esto es una evidencia indirecta de que el valor aspectual que sirve como base para los adjetivos entrante y saliente es estativo. Ahora bien, dado que este valor estativo se construye por encima del Sv, está más allá del dominio de aplicación de -ncia. De hecho, en la jerarquía de Cinque (1999: 99-106), lo que estamos llamando aspecto prospectivo (que admite lectura epistémica), expresado por una perífrasis como ir a + infinitivo, está situado justo debajo del aspecto genérico/progresivo y, en consecuencia, también por debajo del aspecto habitual. Recuérdese que, 
según hemos expuesto más arriba, el aspecto genérico se define como el valor negativo del aspecto episódico (o progresivo), como se muestra en (19):

$$
\text { [AspHabitual }
$$

[Asp [+/-Episódico]

[AspProspectivo

$[\mathrm{Sv}]]]]$

La diferencia en la altura sintáctica en la que se adjunta el sufijo arroja luz sobre la ausencia de paralelismo entre -nte y -ncia, proporcionando un valor predictivo a una explicación basada en dominios sintácticos. En efecto, el paradigma de la Tabla 1 es explicado si los diferentes sufijos operan en diferentes niveles: -nte puede tomar como base lecturas verbales formadas en el dominio del aspecto externo, mientras que -ncia está restringido al dominio del aspecto interno. Podría afirmarse que el alto grado de libertad mostrado por -nte está relacionado con una naturaleza más "verbal". Desde el punto de vista de un enfoque sintáctico (neoconstruccionista) de formación de palabras, la noción de "verbalidad" se entiende como una propiedad escalar (en la línea de Alexiadou 2001; Borer 2003; Alexiadou et al. 2011; Alexiadou et al. 2013; Oltra-Massuet 2014; entre otros). Así, si uno asume que hay dos escalas categoriales: una verbal y otra nominal/adjetival, cada escala contiene un número de propiedades que a su vez se expresan en una serie ordenada de proyecciones sintácticas (cf. Alexiadou et al. 2011). Desde este punto de vista, la distinción entre $\mathrm{V}$ y N/A no es absoluta, sino gradual por naturaleza. Como sostiene Borer (2012, 2013), la naturaleza verbal de un derivado está relacionada con su estructura interna: la cantidad de estructura verbal insertada bajo el núcleo N/A. En este sentido, los datos evidencian que -nte puede seleccionar una estructura sintáctica más compleja (con proyecciones aspectuales), y por tanto ser más "verbal”.

\subsection{La derivación de adjetivos en -nte y nombres en -ncia a partir de especificaciones de dominio estructural}

Hasta donde hemos mostrado empíricamente en este trabajo, -ncia podría describirse como un sufijo nominal que está restringido al dominio del Sv. En este subapartado, desarrollamos brevemente la descomposición semántica del Sv que nos permite dar cuenta de forma más explícita de la distribución de los sufijos. Presentaremos algunos ejemplos concretos de las derivaciones que son posibles de acuerdo con nuestro análisis sintáctico.

Si tomamos como referencia los supuestos asumidos en la literatura sobre la estructura sintáctica del sintagma verbal (Kratzer 1996; Chomsky 2001; Harley 2009; Alexiadou 2012), reconocemos un número fijo de proyecciones dentro de este dominio. Son las siguientes:

- $\quad$ Raíces: piezas de vocabulario sin categoría. No introducen argumentos. Añaden a la derivación un índice fonológico y un significado enciclopédico (cf. Borer 2005a, 2005b y el concepto de listeme) y se insertan en el primer paso de la derivación sintáctica.

- $\quad$ V: proporciona categoría a una raíz e introduce una variable de eventualidad, la cual puede ser un evento (<evento>) o un estado (<estado>) 6 . 
- $\quad$ v: este núcleo introduce el argumento externo, dando lugar a un evento complejo cuando se ensambla con SV. Si V introduce <evento>, el especificador de v recibe el papel temático de Iniciador (en los verbos eventivos transitivos); si V introduce <estado>, entonces tenemos un Poseedor del estado (como ocurre con tener o creer, cf. Kratzer 1996; Alexiadou 2012).

En (20) se representa la descomposición sintáctica del Sv y su relación con las proyecciones funcionales de aspecto externo:

$$
\begin{aligned}
& \text { [ST }[\text { SAsp... } \\
& \text { Aspecto externo }
\end{aligned}
$$$$
\text { [Sv SDIniciador/Poseedor Vo } \text { [sv Voevento/estado> [Raíz] ]]]] }
$$$$
\text { Aspecto interno }
$$

Tomando el esquema de (20) como referencia, la propuesta podría establecerse en los siguientes términos: -ncia sería capaz de tomar una estructura en el dominio de Sv siempre que Vo no introduzca una variable eventiva. No parece que haya una explicación gramatical para dar cuenta de la tendencia mostrada por -ncia a la hora de seleccionar estados, más allá de una explicación histórica o diacrónica. En este sentido, es posible que la productividad de -ncia haya decrecido a causa de la rivalidad con otros sufijos más productivos: principalmente -miento y ción, los cuales tienen un rango de aplicación más amplio, incluyendo eventos y estados ${ }^{7}$. Una vez que -ncia queda restringido a estructuras no eventivas, puede combinarse con estructuras verbales estativas y también con raíces no categorizadas.

Por su parte, -nte viene de un afijo verbal latino, concretamente del afijo de participio de presente, aunque exhibe más restricciones que un participio de presente prototípico. En primer lugar, es cierto que el sufijo puede operar en un nivel estructural alto y seleccionar proyecciones de aspecto externo. Comparte esta propiedad con otros sufijos adjetivadores. Por ejemplo, OltraMassuet (2014) analiza los adjetivos en -ble del español como un tipo de configuración de pasiva modalizada. Parece a primera vista que los sufijos adjetivadores a menudo despliegan menos restricciones de dominio que los sufijos nominalizadores. En segundo lugar, pese a que es cierto que -nte puede seleccionar una estructura verbal más compleja que -ncia, está igualmente restringido a un dominio sintáctico y estructural concreto. Esto es, -nte no puede combinarse con proyecciones aspectuales por encima de AspDisposicional ([-Episódico]) tales como Aspнabitual (cf. 14 supra). En estos casos, el español hace uso de una cláusula finita. Crucialmente, en lenguas que han preservado el valor de participio de presente del sufijo - nt(e), como ocurre con el francés, el sufijo sí puede seleccionar Asp Habitual. Véanse los ejemplos de (21):
(21)

$$
\begin{aligned}
& \text { L'enfant lisant } \\
& \text { 'El niño que lee }
\end{aligned}
$$
des bons livres
est intelligent.
buenos libros
es inteligente'

En español, la construcción sintáctica que equivale al participio de presente del francés en oraciones como la de (21) es la cláusula de relativo, lo que lleva a aventurar que el sufijo - nt del francés opera, al menos, por encima del SAspHabitual. 
Una vez que hemos identificado y aislado las propiedades sintácticas-aspectuales que definen a los sufijos -ncia y -nte, presentamos ahora ejemplos concretos que nos ayudan a mostrar los diferentes tipos de derivados que pueden construirse de acuerdo con cada opción estructural. Procedemos desde los derivados estructuralmente más simples a los más complejos. Así, la primera posibilidad es la adjunción de un sufijo a una raíz desnuda. En este caso, tanto -ncia como -nte pueden dar lugar a una formación léxica, como vemos en (22):

a. excelente

$$
[\mathrm{A}-n t e[\sqrt{\mathrm{EXCELE}-}]]_{\mathrm{A}}
$$

b. excelencia

$$
\left[\mathrm{N}-\text { ncia }\left[\mathrm{V}_{\mathrm{EXCELE}-}\right]\right]_{\mathrm{N}}
$$

En ambos casos, el sufijo categoriza directamente una raíz latina, como ocurre en el par elegante/elegancia, y muchos otros en español. En (22a), obtenemos un predicado («Que sobresale por sus óptimas cualidades», $D L E$, s.v. elegante), mientras que en (22b) obtenemos un nombre de cualidad («Superior calidad o bondad que hace digno de singular aprecio y estimación algo», $D E L$, s.v. elegancia). Las raíces que subyacen a este tipo de derivados, probablemente debido a una razón idiosincrásica, no se han lexicalizado como verbos (*exceler). En este sentido, lo que parece ser una vocal temática (excelente, excelencia) lo ha sido probablemente en el origen etimológico de la palabra, aunque en el análisis sincrónico debería segmentarse como parte de la raíz ${ }^{8}$.

La segunda posibilidad está representada por raíces que se ensamblan debajo de $V_{<\text {estado>, esto }}$ es, verbos marcados como estativos al introducir la variable <estado>. Es el caso de estructuras inacusativas como abundar o existir, ambos verbos de existencia (cf. Alexiadou 2012). Véase (23):

abundar

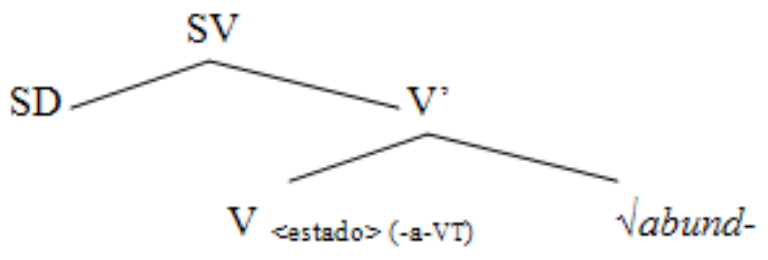

En (23) el verbo abundar se representa como una estructura verbal sin argumento externo. Esta estructura se adjetiviza cuando se ensambla debajo de $-n t e$, mientras que se nominaliza cuando se ensambla debajo de -ncia, como en (24):
a. abundante

$$
\left[\mathrm{A}-n t e\left[\mathrm{sv} \mathrm{V}_{<\mathrm{estado}}>(-a-\mathrm{vT})[\sqrt{\mathrm{ABUND}}-]\right]\right]_{\mathrm{A}}
$$

b. abundancia 


$$
\left[\mathrm{N}-n c i a\left[\mathrm{sv}\left[\mathrm{V}_{<\mathrm{estado}}(-\boldsymbol{a}-\mathrm{VT})[\sqrt{\mathrm{ABUND}}-]\right]\right]_{\mathrm{N}}\right.
$$

Nótese que, en el caso de los verbos transitivos de estado, Sv se proyecta e introduce el argumento externo (Poseedor) en su especificador, como le ocurre a tener o creer, los cuales asignan caso acusativo: lo cree, lo tiene. En (25) aparece representada la estructura de estos verbos:

(25) creer

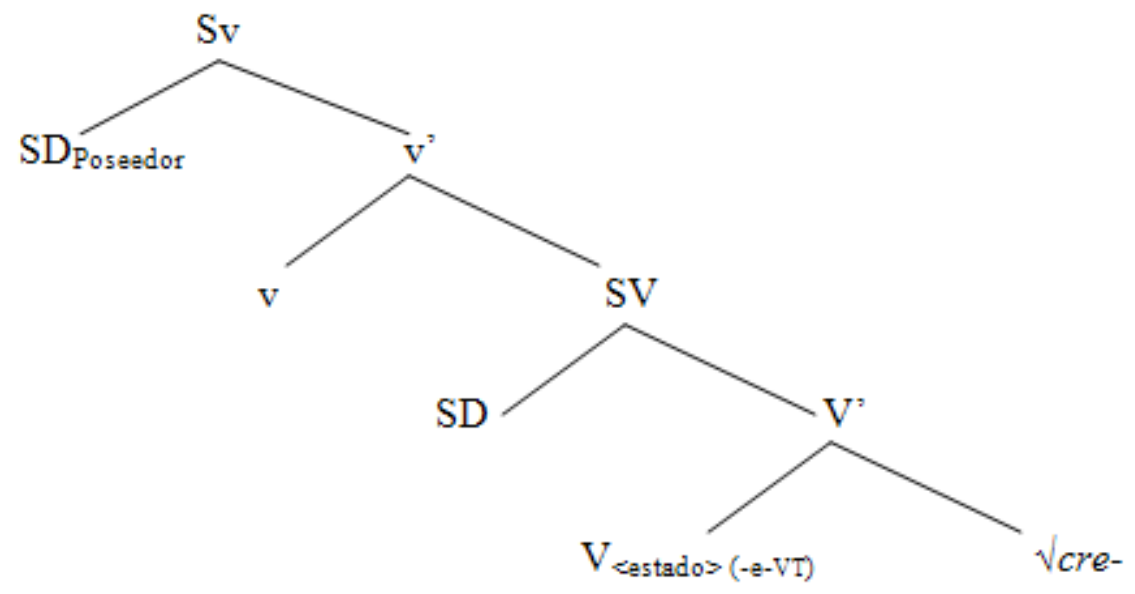

En (25), el SD en [Espec, Sv] se interpreta como el creyente, mientras que el SD en la posición de argumento interno ([Espec, SV]) corresponde al objeto tema. Nuevamente, esta estructura verbal puede ser bien adjetivizada por el sufijo -nte, dando lugar a un adjetivo (creyente), o nominalizada por el sufijo -ncia, dando lugar a un nombre (creencia). Estas dos opciones están representadas en (26), respectivamente:

a. creyente

$$
[\mathrm{A}-n t e[\mathrm{~Sv} \mathrm{~V}[\mathrm{sv} \mathrm{SD}[\mathrm{V}<\mathrm{estado}>(-e-\mathrm{vT})[\sqrt{\mathrm{CRE}-}]]]]]_{\mathrm{A}}
$$

b. creencia

$$
\left[\mathrm{N}-n c i a\left[\mathrm{~Sv} \mathrm{v}\left[\mathrm{sv} \mathrm{SD}\left[\mathrm{V}_{<\mathrm{estado}>}(-e-\mathrm{vT})[\sqrt{\mathrm{CRE}}-]\right]\right]\right]\right]_{\mathrm{N}}
$$

Finalmente, una vez que hemos revisado los derivados construidos en el dominio de Sv, vamos a tratar los adjetivos derivados a partir de una estructura verbal de aspecto disposicional. Hay que recordar que, de acuerdo con nuestra propuesta, el aspecto disposicional/genérico corresponde a una proyección funcional de aspecto externo que cambia la naturaleza dinámica original del predicado. Representamos esto mediante un operador disposicional en el núcleo Asp que liga la variable de evento introducida por Voo, dando lugar a una lectura no eventiva. Si recordamos lo discutido en el §4.1, el valor disposicional/genérico puede entenderse, en términos de la jerarquía de Cinque (1999), como el valor no marcado de un nodo aspectual episódico. Un modo alternativo de especificar esta idea es, como se ilustra en (27), formular la lectura disposicional como un 
operador aspectual que impide el cierre existencial del argumento eventivo contenido en Sv y, con ello, el valor episódico de la estructura en su conjunto (cf. nota 4 supra). Al margen de la formulación específica adoptada, la consecuencia empírica del análisis es que, asumiendo que el valor disposicional es más alto que el aspecto léxico codificado en el Sv, pero más bajo que el aspecto habitual, la configuración resultante no denota un evento sino una propiedad asociada a él.

(27) cortar

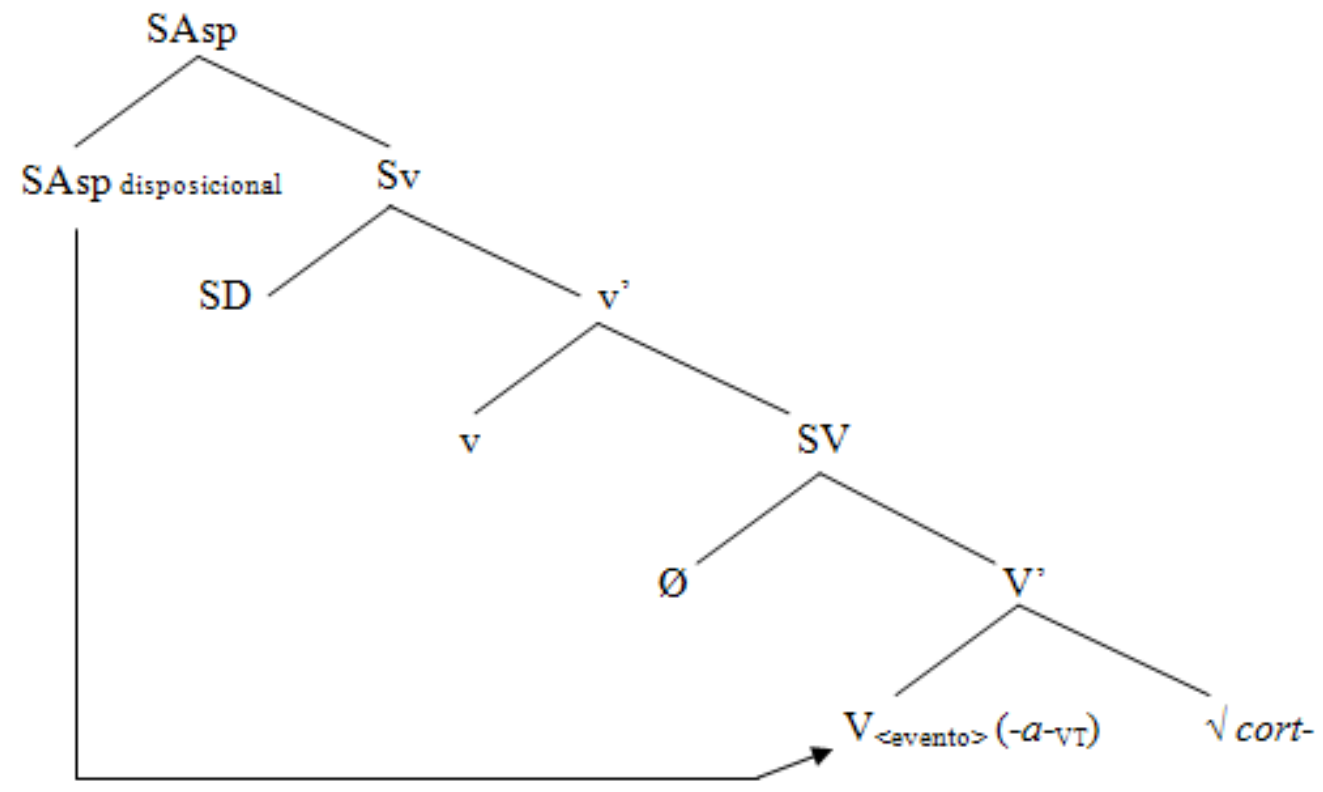

Cuando -nte selecciona esta estructura, se obtienen adjetivos de lectura disposicional:

cortante

$\left[\mathrm{A}-n t e\left[\mathrm{~s} A s p \text { Asp [disposicional] }\left[\mathrm{Sv}\left[\mathrm{sv} \varnothing\left[\mathrm{V}_{\text {eavento }}(-a-\mathrm{vT})[\sqrt{ } \mathrm{CORT}-]\right]\right]_{\mathrm{V}}\right]\right]_{\mathrm{A}}\right.$

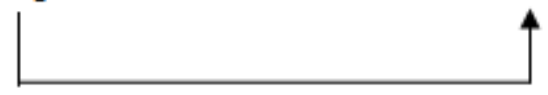

Cerramos este apartado recordando que hay dos razones que pueden explicar la ausencia de sustantivos del tipo de cortancia. La primera es que el sufijo no se puede ensamblar dentro de la estructura construida en el Sv, dado que este contiene un argumento eventivo que codifica un predicado dinámico; produciéndose, por tanto, una incompatibilidad aspectual. La segunda razón es que, aunque el significado obtenido por encima del Sv sí satisfaga su caracterización aspectual, esta queda por encima de su dominio estructural. 


\section{ALGUNAS CONSECUENCIAS DE ESTE ANÁLISIS: LA (IN)DEPENDENCIA DE -NTE Y -NCIA}

El análisis que acabamos de presentar muestra que -nte y -ncia son dos sufijos que deberían ser tratados de manera independiente, con sus correspondientes especificaciones estructurales. En este sentido, nuestra propuesta contribuye de manera significativa al estudio de un problema tradicional que se ha observado en la morfología descriptiva del español. Esto es, algunos autores han señalado que estos sufijos están íntimamente relacionados tanto desde el punto de vista diacrónico como sincrónico (Santiago \& Bustos 1999; Pharies 2002). En esta sección revisamos en detalle la relación derivativa entre -nte y -ncia. En concreto, mostramos que, aunque hay razones diacrónicas y descriptivas para apoyar una derivación -nte > -ncia, esta no es la opción apropiada para el español actual, donde la evidencia empírica sugiere que cada sufijo funciona como una pieza de vocabulario independiente. Esta imagen encaja con nuestro análisis: si -ncia se concibe como la versión nominal de -nte, los huecos exhibidos por el primero necesitarían asunciones y explicaciones probablemente ad hoc. En cambio, si -ncia es tratado como un sufijo nominal deverbal, la ausencia de paralelismo con -nte se sigue de propiedades independientes de la gramática del español.

Desde un punto de vista diacrónico e histórico, los sufijos -nte y -ncia han estado estrechamente relacionados. Pharies (2002: 202) afirma sobre -ncia: «Es un sufijo derivado de -entia, -ae, un sufijo compuesto del latín cuyos constituyentes internos son -(i)ent (-ente), el afijo del participio de presente, y el sufijo -ia». En esta línea, Santiago \& Bustos (1999: 4581) han propuesto, entre otros, el análisis de (29) para explicar los nombres en -ncia dentro de un enfoque morfológico sincrónico:

$$
\left[[[[\text { raíz verbal }] \text { vocal temática }]-n t e]_{\mathrm{A}}-i a\right]_{\mathrm{N}}
$$

Este análisis postula un sufijo nominal -ia que es añadido a los adjetivos que acaban en -nte, dando lugar a nombres en -ncia por medio de un cambio fonológico de $/ \mathrm{t} /<\mathrm{t}\rangle \mathrm{a} / \theta /<\mathrm{c}>$. Hay algunos datos empíricos que apoyan este análisis. Por un lado, un gran grupo de pares -ncia/-nte no tienen en la base un verbo derivativo en común, de forma que el nombre en -ncia se uniría directamente al adjetivo en -nte correspondiente. Considérense los ejemplos de (30):

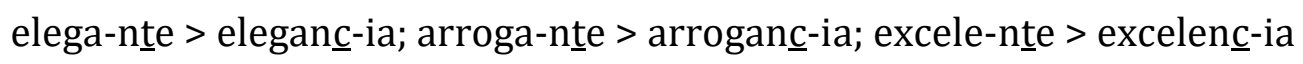

En una primera aproximación, los nombres en -ncia de (30) parecen ser nombres de cualidad. Por ejemplo, elegancia se define como la «Cualidad de ser elegante» (DEL, s.v. elegancia). Sin embargo, la paráfrasis semántica y el consecuente orden derivativo $-n t e>-n c i a$ podría ser problemático. De hecho, si nos basamos únicamente en un criterio semántico-lexicográfico, el orden derivativo podría ser también el opuesto: elegante puede ser definido como 'Dotado de elegancia', mostrando la derivación -ncia $>-n t e$. Como alternativa a este dilema derivacional, los derivados de (30) pueden verse como ejemplos de la inserción de una misma raíz bajo una 
proyección nominal o adjetival —es decir, una derivación paralela a partir de una base común-, antes que como una secuencia de dos procesos derivativos.

Asimismo, es cierto que algunos datos apoyan una relación sincrónica estrecha entre -nte y ncia. En la Tabla 3 tenemos algunos ejemplos de convergencias semánticas. A pesar de compartir la misma fuente verbal, los derivados adquieren un significado no composicional o atómico, que no está disponible para el verbo con el que aparentemente exhiben una relación formal.

Tabla 3. Ejemplos de convergencia semántica de -nte y-ncia

\begin{tabular}{|l|l|l|}
\hline \multicolumn{1}{|c|}{$\mathbf{V}$} & \multicolumn{1}{|c|}{$-\boldsymbol{n t e}$} & \multicolumn{1}{c|}{-ncia } \\
\hline consistir & consiste-nte & consiste-ncia \\
\hline constar & consta-nte & consta-ncia \\
\hline competir & compete-nte & compete-ncia \\
\hline
\end{tabular}

En efecto, si observamos el primer ejemplo de la Tabla 3, entendemos que se puede decir de una declaración que es consistente o que tiene consistencia, en ambos casos aduciendo a su solidez lógica, pero no tendría sentido decir, con este mismo valor semántico, que una declaración consiste.

Otro argumento a favor del análisis representado en (29) -en el que -ia es un sufijo nominalizador- es el tratamiento unificado que recibirían otros nombres del español formados sobre adjetivos. Véanse a este respecto los siguientes ejemplos:
a. audazA
$>\quad$ audac-ian
b. eficazA
$>\quad$ eficac-ian

Asimismo, este análisis daría cuenta también de la derivación de nombres que tienen como base léxica un adjetivo que acaba, en este caso, en -lento (Lang 1992; NGLE: §6.3q):

$$
\text { opu-lento } \quad>\quad \text { opu-lenc-ian }
$$

Por extensión, el ejemplo de (32) debería analizarse de la misma forma que los ejemplos de (30), asumiendo otra vez un cambio fonológico de /t/ a / $\theta /$. Sin embargo, no está claro que -ia esté funcionando realmente como una pieza de vocabulario activa para formar nombres a partir de adjetivos en la morfología sincrónica del español. Primero, hay pocas bases con las que se combina, y estas han sido recibidas directamente del latín: opulentǐa ya era la nominalización de opǔlens, ntis y ambos fueron transferidos al español como palabras ya formadas (NGLE: §6.3q). Segundo, parece que el significado proporcionado por -ia no es composicional ni transparente, contrariamente a lo que se esperaría de un proceso morfológico productivo. Por ejemplo, si 
observamos los nombres de (33), su paráfrasis no coincide con el significado de nombre de cualidad asociado con los ejemplos de (30)-(32):
a. falaz
$>$
falac-ia («Engaño, fraude o mentira con que se intenta dañar a alguien», $D L E$, s.v. falacia)
b. infante
$>$
infanc-ia («Periodo de la vida humana desde el nacimiento hasta la pubertad», DEL, s.v. infancia)

Una vez que hemos expuesto los problemas que plantean los argumentos para adoptar un análisis donde -ia se adjunta a -nte, con el consabido cambio fonológico de $/ \mathrm{t} /\langle\mathrm{t}\rangle \mathrm{a} / \theta /\langle\mathrm{c}\rangle$, presentamos ahora datos empíricos que apoyan un análisis diferente, donde -ncia es una pieza de vocabulario independiente, como ha sido sugerido también por los propios Santiago \& Bustos o más recientemente Fábregas (2016). En este caso, -ncia se une directamente a un verbo, evadiendo la derivación a partir de un posible adjetivo en -nte, como se muestra en (34):

$$
\left[[[\text { raíz verbal] vocal temática }]-n c i a]_{\mathrm{N}}\right.
$$

Este análisis descansa sobre el hecho de que, aunque hay razones para pensar que hay una relación estrecha entre -ncia y -nte, algunos contextos empíricos demuestran la independencia de -ncia como sufijo nominal. Por un lado, en (35) observamos una lista de nominalizaciones deverbales en -ncia que carecen del adjetivo en -nte correspondiente:

\begin{tabular}{|c|c|c|c|c|}
\hline (35) a. ganar & $>$ & ganancia & / & *ganante \\
\hline b. inferir & $>$ & inferencia & / & *inferente \\
\hline c. interferir & $>$ & interferencia & / & *interferente \\
\hline d. querer & $>$ & querencia & / & *queriente \\
\hline
\end{tabular}

Considerando estos ejemplos, uno podría verse tentado a afirmar que la ausencia de un derivado en -nte se explica como un caso de bloqueo morfológico, porque ya existe un proceso derivativo relacionado (Aronoff 1976). Así, por ejemplo, se puede pensar en ganador, construido sobre el verbo ganar y -dor, un sufijo estrechamente relacionado con -nte. Sin embargo, no hay *inferi-dor $(<$ inferir), *interferi-dor (< interferir) o *quere-dor (< querer), que podrían explicar el hueco léxico del correspondiente derivado en -nte. Por otro lado, hay casos en los que encontramos una base léxica común, que puede ser ligeramente diferente para cada derivado. Tenemos un ejemplo en (36):
(36)
a. influev-ncian
b. influyev-nte 
Estos ejemplos no pueden explicarse si uno de los sufijos se aplica sobre el derivado formado por el otro. Si hubiera una relación derivativa entre -ncia y -nte, de forma tal que el primero seleccione al segundo (es decir, -ncia se deriva a partir de -nte), el resultado esperado para (36a) sería *influyencia (de influyente), dado que los procesos derivativos típicamente preservan la estructura morfológica de la base que contienen a través de la derivación ${ }^{9}$.

Por último, mientras las convergencias semánticas pueden usarse para defender la derivación -nte > -ncia (cf. Tabla 3), hay también casos de divergencias semánticas que apoyan la independencia de estos sufijos. En (37) tenemos dos ejemplos:
a. tenerv
$>\quad$ tene-ncia
/ tenie-nte
b. permanecerv
$>\quad$ permane-ncia
/ permane-nte

En (37), solo los nombres en -ncia cuentan como la expresión nominal del predicado verbal, mientras que las formaciones en -nte implican bien un cambio radical de significado, como con teniente, o un matiz aspectual ausente en la base, como en permanente. Este adjetivo añade la idea de que una situación dada no puede ser revertida, y no solo que cierta situación se mantiene durante un periodo de tiempo. Esta ausencia de paralelismo se ilustra en los siguientes ejemplos:

(38) a. El hombre permaneció cinco minutos en la habitación.

b. La permanencia del hombre durante cinco minutos en la habitación.

c. *El/un hombre permanente durante cinco minutos en la habitación.

Es interesante hacer notar en estos casos que la conciencia del hablante disocia semánticamente los nombres en -ncia de los adjetivos en -nte. Si hubiera una relación derivativa entre los sufijos, se esperaría que el valor idiosincrásico asociado con el adjetivo en -nte (e.g. teniente o permanente) estuviera disponible al menos para el correspondiente nombre en -ncia, construido sobre el adjetivo. Pero este no es el caso ni para tenencia ni para permanencia, que parecen estar directamente relacionados con la base verbal, "saltándose" el significado idiosincrásico del adjetivo (cf. Marantz 2014, para algunos ejemplos análogos en inglés).

En resumen, en esta sección hemos revisado diferentes datos que apoyan tanto una derivación -nte > -ncia como un tratamiento independiente para cada sufijo. Como venimos defendiendo a lo largo de este trabajo, la última opción parece proporcionar una imagen más apropiada para el español actual. El análisis presentado en las secciones previas inclina la balanza en favor de la segunda hipótesis. Efectivamente, cada sufijo tiene sus propias especificaciones de dominio $\mathrm{y}$, para comprender completamente las restricciones impuestas sobre - ncia, el último tiene que concebirse como un sufijo nominal deverbal. 


\section{CONCLUSIÓN}

En este artículo hemos revisado el impacto que el contenido aspectual puede tener sobre la derivación morfológica. Específicamente, hemos puesto el foco en la distribución de los adjetivos en -nte y los nombres en -ncia, los cuales han constituido un problema clásico para el estudio de la derivación en español. Asumiendo un enfoque neoconstruccionista, hemos mostrado que la distribución de estos afijos puede explicarse apelando a niveles o dominios estructurales (sintácticos) diferentes. En particular, hemos propuesto que la ausencia sistemática exhibida por los nombres en -ncia en el caso de los verbos eventivos bajo lectura disposicional (e.g. * cortancia) puede explicarse si restringimos el dominio de aplicación del sufijo nominal a la primera fase (Sv). Por el contrario, -nte puede operar en el nivel del aspecto externo, por encima de Sv y, por tanto, dar lugar a adjetivos con lectura disposicional.

Una especificación sintáctica más detallada indica que -ncia puede ser adjuntado a cualquier nivel, con preferencia por estructuras que carecen de un argumento <evento>. Entonces, puede ensamblarse con raíces (elegancia), SV (abundancia) y Sv (creencia), pero en general no es compatible con verbos dinámicos (esto es, estructuras que tienen la variable <evento>). Para $-n t e$, hemos propuesto que, mientras que puede operar por encima de Sv -como ocurre con cortante, cuya lectura disposicional es construida en el dominio del aspecto externo, específicamente [Episódico], siguiendo la formulación derivada de Cinque (1999)—, está sin embargo excluido de proyecciones más altas, como el Aspecto Habitual.

En síntesis, este trabajo muestra evidencia de que la sensibilidad aspectual de los procesos derivativos puede establecerse en términos sintácticos. Bajo el análisis desarrollado aquí, hay que remarcar que la noción de 'estatividad' por sí misma no proporciona un criterio suficiente para la aceptabilidad de -ncia. Hemos visto que es crucial añadir la noción de nivel de estatividad, esto es, no solo si un predicado dado es estativo o no, sino dónde (a qué altura estructural) se adquiere tal estatividad. Esto nos da el grado de detalle que necesitamos para dar cuenta de la distribución de los sufijos sin introducir en la gramática complejidades innecesarias.

\section{Agradecimientos}

Agradecemos a Josefa Martín la lectura minuciosa y atenta y los comentarios hechos a una primera versión de este trabajo.

\section{Bibliografía}

Alexiadou, A. (2001): Functional Structure in Nominals: Nominalization and Ergativity. Amsterdam: John Benjamins. https://doi.org/10.1075/la.42.

AlEXIADOU, A. (2009): "On the role of syntactic locality in morphological processes: the case of (Greek) derived nominals", en A. GIANNAKIDOU \& M. RATHERT (eds.): Quantification, Definiteness and Nominalization. Oxford: Oxford University Press, pp. 253-280. 
AleXIAdoU, A. (2011): “The aspectual properties of nominalization structures”, en A. GALANI, G. HiCKS \& G. TSOULAS (eds.): Morphology and its interfaces. Amsterdam: John Benjamins, pp. 195-220. https://doi.org/10.1075/la.178.11ale.

Alexiadou, A. (2012): "Statives and nominalization", Recherches Linguistiques de Vincennes 40, pp. 25-52. https://doi.org/10.4000/rlv.1991.

Alexiadou, A. \& GRIMSHAW, J. (2008): “Verbs, nouns and affixation”, en F. SchäFER (ed.): SinSpeC (1): Working Papers of the SFB 732. Stuttgart: University of Stuttgart, pp. 1-16.

Alexiadou, A., IORDĂCHIOAIA, G. \& SCHÄFER, F. (2011): "Scaling the variation in Romance and Germanic Nominalizations", en P. SleEMAn \& H. PERRIDON (eds.): The Noun Phrase in Romance and Germanic. Amsterdam: Johns Benjamins, pp. 25-40. https://doi.org/10.1075/la.171.04ale.

Alexiadou, A., IORDĂCHIOAIA, G. \& SOARE, E. (2010): "Number/Aspect interactions in the syntax of nominalizations: a distributed morphology approach", Journal of Linguistics 46, pp. 537-574. https://doi.org/10.1017/S0022226710000058.

Alexiadou, A. \& SchäFER, F. (2010): “On the syntax of episodic vs. dispositional -er nominals", en A. AleXIADOU \& M. RATHERT (eds.): The Syntax of Nominalizations across Languages and Frameworks. Berlin: De Gruyter Mouton, pp. 9-38. https://doi.org/10.1515/9783110245875.9.

Alexiadou, A., Iordăchiofia, G., CANO, M. a A., Martin, F. \& SchäFER, F. (2013): "The realization of external arguments in derived nominals", Journal of Comparative Germanic Linguistics 16. Springer, pp. 73-95. https://doi.org/10.1007/s10828-014-9062-x.

ARonofF, M. (1976): Word formation in Generative Grammar. Cambridge: MIT Press.

BACH, E. (1986): “The algebra of events”, Linguistics and Philosophy 3, pp. 5-16.

Borer, H. (2003): "Exo-skeletal vs. endo-skeletal explanation: Syntactic projection and the lexicon", en J. Moor \& M. PoLINSKY (eds.): The Nature of Explanation in Linguistic Theory. Stanford: CSLI, pp. 31-67.

Borer, H. (2005a): Structuring Sense, Vol. I: In Name Only. Oxford: Oxford University Press. https://doi.org/10.1093/acprof:oso/9780199263905.001.0001.

Borer, H. (2005b): Structuring Sense, Vol. II: The Normal Course of Event. Oxford: Oxford University Press. https://doi.org/10.1093/acprof:oso/9780199263929.001.0001.

Borer, H. (2012): “In the Event of a Nominal”, en M. Everaert, M. Marelu \& T. Siloni (eds.): The Theta System: Argument Structure in the Interface. Oxford: Oxford University Press, pp. 103-150.

Borer, H. (2013): Structuring Sense, Vol. III: Taking form. Oxford: Oxford University Press. https://doi.org/10.1093/acprof:oso/9780199263936.001.0001.

CANO, M. - A (2013): Las derivaciones en -nte y -dor: Estructura argumental y complejidad sintáctica en una morfología neoconstruccionista. Tesis Doctoral. Madrid: Universidad Autónoma de Madrid.

CARLSON, G. (2012): "Habitual and Generic Aspect”, en I. RoBert Binnick (ed.): The Oxford Handbook of Tense and Aspect. Oxford: Oxford University Press, pp. 828-851. https://doi.org/10.1093/oxfordhb/9780195381979.013.0029.

Сномsкy, N. (2001): “Derivation by Phase”, en M. Kenstowicz (ed.): Ken Hale: A Life in Language. Cambridge: MIT Press, pp. 1-52.

Cinque, G. (1999): Adverbs and Functional Heads. New York: Oxford University Press.

CoRnilescu, A. (2001): "Romanian Nominalizations: Case and Aspectual Structure”, Journal of Linguistics 37:3, pp. 467-501. https://doi.org/10.1017/S0022226701001074. 
DAHL, O. (1985): Tense and Aspect Systems. Oxford: Blackwell.

De Belder, M. \& VAN CRAENENBRoECK, J. (2015): “How to merge a root”, Linguistic Inquiry 46(4), pp. 625-655. https://doi.org/10.1162/LING a 00196.

DE Miguel, E. (1996): “Nominal Infinitives in Spanish: An Aspectual Constraint”, Canadian Journal of Linguistics 41:1, pp. 29-54. https://doi.org/10.1017/S0008413100020247

De Miguel, E. (1999): “El aspecto léxico”, en I. Bosque \& V. Demonte (dirs.): Gramática Descriptiva de la Lengua Española, v. 2, cap. 46. Madrid: Espasa- Calpe, pp. 2977-3059.

DLE = REAL ACADEmia EsPañola: Diccionario de la lengua española, 23. a ed., [versión 23.4 en línea]. $<$ https://dle.rae.es>

Embick, D. \& R. Noyer (2007): "Distributed Morphology and the Syntax-Morphology Interface”, en G. RAMCHAND \& C. REIS (eds.): The Oxford Handbook of Linguistic Interfaces. Oxford: Oxford University Press, pp. 289-324. https://doi.org/10.1093/oxfordhb/9780199247455.013.0010.

FÁBREGAS, A. (2010): “A syntactic account of affix rivalry in Spanish nominalizations”, en A. AlEXIADOU \& M. RATHERT (eds.): The syntax of nominalizations across languages and frameworks. Berlin: Mouton de Gruyter, pp. 67-92. https://doi.org/10.1515/9783110245875.67.

FÁBREGAS, A. (2014): "Argument structure and morphologically underived nouns in Spanish and English", Lingua 141, pp.97-120. https://doi.org/10.1016/j.lingua.2013.02.011.

FÁBREGAS, A. (2016): Las nominalizaciones. Madrid: Visor.

FÁBREGAS, A. \& MARÍN, R. (2012): “The role of Aktionsart in deverbal nouns: State nominalizations across languages", Journal of Linguistics 48, pp 35-70. https://doi.org/10.1017/S0022226711000351.

FERnÁndez LEBorans, M. \& SÁnChEZ, C. (2015): “On events that express properties”, en E. BARRAJón, J. CifuEnTES \& S. RodRíGUEZ (eds.): Verb classes and aspect. Amsterdam: John Benjamins, pp. 238-263. https://doi.org/10.1075/ivitra.9.11fer.

FELÍU, E. (2012): “La formación de nombres de lugar en -dero en español actual”, en E. BERNAL, C. SiNNER \& M. EMSEL (eds.): Tiempo y espacio en la formación de palabras en español. Munich: Peniope, pp. 123-137.

FUNDÉU RAE. "Buscador urgente de dudas", https://www.fundeu.es/ [10.12.2008]

GRIMSHAW, J. (1990): Argument Structure, Linguistic Inquiry Monographs 18. Cambridge: MIT Press.

HALLMAN, P. (2010): “Instants and intervals in the event/state distinction”. Ms. UCLA.

HARLEY, H. (2009): "The morphology of nominalizations and the syntax of vP", en M. RATHERT \& A. GianNADikou (eds.): Quantification, Definiteness and Nominalization. Oxford: Oxford University Press, pp. 321-343.

HARLEY, H. (2012): "Lexical decomposition in modern syntactic theory", en W. HINZEN, E. MACHERY \& M. WERNING (eds.): The Oxford Handbook of Compositionality. Oxford: Oxford University Press, pp. 328350. https://doi.org/10.1093/oxfordhb/9780199541072.013.0015.

Horno ChÉliZ, M. (2011): “Argumento eventivo, estados léxicos y enunciados estativos”, en A. CARRASCO (ed.): Sobre estados y estatividad. Munich: LINCOM, pp. 63-82.

JAQUE, M. (2014): La expresión de la estatividad en español: niveles de representación y grados de dinamicidad. Tesis Doctoral. Madrid: Universidad Autónoma de Madrid.

JAQUE, M. (2016): "Relaciones entre aspecto y modalidad epistémica: algunas consecuencias de las restricciones temporales sobre la evaluación de predicados”, Onomázein 33, pp. 130-155. https://doi.org/10.7764/onomazein.33.6. 
Jaque, M. \& MARTín GarcíA, J. (2012): “Configurational constraints on noneventive nominalizations in Spanish", Norlyd 39.1, special issue, K. BENTZEN \& A. FÁBREGAS (eds.): The Grammar of Objects. Tromsoe: University of Tromsø, pp. 113-140. https://doi.org/10.7557/12.2290.

KATZ, G. (2000): “Anti neo-Davidsonianism: against a Davidsonian semantics for state sentences”, en J. PUSTEJOVSKY \& C. TENNY (eds.): Events as Grammatical Objects. The converging perspectives of lexical semantics and syntax. Standford: CSLI, pp. 393-416.

Kratzer, A. (1996): "Severing the External Argument from its Verb”, en J. RoorycK \& L. ZARING (eds.): Phrase Structure and the Lexicon. Dordrecht: Kluwer, pp. 109-137. https://doi.org/10.1007/978-94-0158617-7 5.

LANG, M. (1992): Formación de palabras en español. Madrid: Cátedra.

LEKAKou, M. (2005): In the Middle, Somewhat Elevated. The semantics of middles and its crosslinguistic realization. PhD Dissertation: University of London.

LUNDQUIST, B. (2012): "Localizing cross-linguistic variation in Tense systems: on telicity and stativity in Swedish and English", Nordic Journal of Linguistics 35(1), pp. 27-70. https://doi.org/10.1017/S033258651200011X.

MAIEnBoRn, C. (2005): "On the limits of The Davidsonian approach: The case of copula sentences", Theoretical Linguistics 31, pp. 275-316. https://doi.org/10.1515/thli.2005.31.3.275.

MARANTZ, A. (1997): “No Escape from syntax. Don't try morphological analysis in the privacy of your own lexicon”, UPenn Working Papers in Linguistics 4, pp. 201-225.

MARANTZ, A. (2014): “Locality Domains for Contextual Allomorphy across the Interfaces", en 0. MATUSHANSKY \& A. MARANTZ (eds.): Distributed Morphology Today: Morphemes for Morris Halle. Cambridge, $\quad$ MA: MIT $\quad$ Press, $\quad$ pp. https://doi.org/10.7551/mitpress/9780262019675.003.0006.

MARCHIS, M. (2008): “The internal structure of the -or nominalization in Romanian”, en F. SCHÄFER (ed.): Working Papers of the SFB 732 Incremental Specification in Context. Stuttgart, pp. 103-117.

MARÍN, R. (2013): La stativité dans tous ses états. Memoire de Habilitation, Lille, France.

MARTin, F. (2008): Les prédicats statifs. Étude sémantique et pragmatique. Paris/Bruxelles: Duculot/De Boeck. https://doi.org/10.3917/dbu.marti.2008.01.

MARTín GARCÍA, J. (2011): “Deverbal nouns with the suffix -dura”, en J. L. CifuEnTES \& S. RodRÍGUEZ (eds.): Spanish Word Formation and Lexical Creation. Amsterdam: John Benjamins, pp. 165-183. https://doi.org/10.1075/ivitra.1.07gar.

Narrog, H. (2012): Modality, Subjectivity, and Semantic Change. A Cross-Linguistic Perspective. Oxford: Oxford University Press. https://doi.org/10.1093/acprof:oso/9780199694372.001.0001.

$N G L E=$ REAL ACADEMIA ESPAÑOLA Y ASOCIACIÓN DE ACADEMIAS DE LA LENGUA ESPAÑOLA (2009): Nueva Gramática de la Real Academia de la Lengua Española. Madrid: Espasa.

Oltra-Massuet, I. (1999): “On the Constituent Structure of Catalan Verbs”, en K. Arregi, B. Bruening, C. KraUSE \& V. Lin (eds.): MITWPL 33: Papers in Morphology and Syntax, Cycle One. Cambridge (Mass.): MIT Press, pp. 279-322.

OLtRA-MASSUET, I. (2010): On the morphology of complex adjectives. Tesis Doctoral. Barcelona: Universidad Autónoma of Barcelona. 
Oltra-Massuet, I. (2014): Deverbal Adjectives at the Interface: A Crosslinguistic Investigation into the Morphology, Syntax and Semantics of -ble. Berlin: Mouton de Gruyter. https://doi.org/10.1515/9781614510659.

Oltra-MASSUET, I. \& ARREGI, K. (2005): “Stress-by-Structure in Spanish”, Linguistic Inquiry 36(1), pp. 43-84. https://doi.org/10.1162/0024389052993637.

PARSONS, T. (1990): Events in the Semantics of English. Cambridge: MIT Press.

PHARIES, D. (2002): Diccionario etimológico de los sufijos españoles y de otros elementos finales. Madrid: Gredos.

Ramchand, G. (2008): Verb Meaning and the Lexicon. Cambridge: Cambridge University Press. https://doi.org/10.1017/CB09780511486319.

Ramchand, G. (2018): Situations and Syntactic Structures. Rethinking Auxiliaries and Order in English. Cambridge: The MIT Press. https://doi.org/10.7551/mitpress/9780262037754.001.0001.

RAmChand, G. \& Svenonius, P. (2014): “Deriving the functional hierarchy”, Language Sciences 46, pp. 152174. https://doi.org/10.1016/j.langsci.2014.06.013.

RothmaYR, A. (2009): The Structure of Stative Verbs. Amsterdam: John Benjamins. https://doi.org/10.1075/la.143.

Roy, I. (2013): Nonverbal Predication. Copular Sentences at the Syntax-Semantics Interface. Oxford: Oxford University Press. https://doi.org/10.1093/acprof:oso/9780199543540.001.0001.

ROY, I. \& SOARE, E. (2012): “L'enquêteur, le surveillant et le détenu: les noms déverbaux de participants aux événements, lectures événementielles et structure argumentale”, en R. MARín \& F. VILLOING (eds.): Lexique 20: Nouveaux aspects sur les Nominalisations. Presses Universitaires du Septentrion: Villeneuve d'Ascq, pp. 207-231.

SAntiago, R. \& Bustos. E. (1999): "La derivación nominal”, en I. Bosque \& V. Demonte (dirs.): Gramática Descriptiva de la Lengua Española, vol. 3, cap. 69. Madrid: Espasa Calpe, pp. 4505-4590.

SCHEINER, J. M. (2002): “Temporal anchoring of habituals”, en M. VAN KoPPEN, J. Sio \& M. DE Vos (eds.): Proceedings of ConSole XI. The Netherland: Leiden University. Recuperado de https://www.universiteitleiden.nl/binaries/content/assets/geesteswetenschappen/lucl/sole/cons ole-xi.pdf [02.01.2020]

SICHEL, I. (2010): "Event-structure constraints on nominalizations”, en A. AlEXIADOU \& M. RATHERT (eds.): The syntax of nominalizations across languages and frameworks. Berlin: Mouton de Gruyter, pp. 159198. https://doi.org/10.1515/9783110245875.159.

Soто, G. (2008): "Sobre el llamado futuro de probabilidad. Algunas condiciones del valor modal de -ré", Boletín de Filología Tomo XLIII, pp. 193-206.

VARELA, S. (2012): "La interacción de las nominalizaciones con la voz, el aspecto y la dimensión temporal”, en E. BERNAL, C. SinNer \& M. EMSEl (eds.): Tiempo y espacio en la formación de palabras en español. Munich: Peniope, pp. 91-106.

VERKUYL, H. (1993): A Theory of Aspectuality: The Interaction between Temporal and Atemporal Structure. Cambridge: Cambridge University Press. https://doi.org/10.1017/CB09780511597848.

Wiltschко, M. (2014): The universal structure of categories. Cambridge: Cambridge University Press. https://doi.org/10.1017/CB09781139833899. 


\section{Notas}

${ }^{1}$ Un verbo de acción —como evento dinámico- ocurre, tiene lugar, avanza, implica un cambio o progreso a lo largo del intervalo de tiempo en que ocurre. Por su parte, un evento no dinámico — de estado— no ocurre, no tiene lugar, no implica cambio o modificación durante el periodo de tiempo en el que se extiende (De Miguel 1999: 3012).

${ }^{2}$ Es interesante mencionar que el contraste observado en la Tabla 1 entre el adjetivo en -nte y la ausencia del nombre en -ncia está presente en otras lenguas como el francés y el inglés.

\begin{tabular}{lll} 
& Francés & Inglés \\
\hline Paradigma regular & distant(e) - distance & distant - distance \\
Paradigma roto & fertilisant(e) - *fertilisance & fertilizing - *fertilizance \\
& exfoliant(e) - *exfoliance & exfoliant - *exfoliance
\end{tabular}

Por un lado, en el caso del francés, el sufijo -nt(e) es diferente del español -nte en la medida en que puede funcionar como participio de presente. Pero puede ser también un adjetivo (e.g. un gel exfoliant 'un gel exfoliante'). El punto relevante es que los adjetivos derivados de los verbos listados en la Tabla 1 tampoco tienen correlato nominal en -ncia (-ance) en francés. Por otro lado, la contrapartida en inglés de algunos adjetivos en -nte con significado disposicional son -ing o-er, los cuales son a menudo sufijos más productivos. En cualquier caso, el punto crucial es otra vez la ausencia de nombres en -ncia (-ance). Estos datos sugerirían que el patrón derivativo que hemos descrito para -nte y -ncia en español no parece ser un fenómeno idiosincrásico del español, sino más bien un fenómeno estructural, dado que en otras lenguas con antecedentes latinos los datos son similares.

3 En este trabajo asumimos que la diferencia entre aspecto interno y externo puede formularse en términos de una diferencia entre fases sintácticas, de forma tal que el aspecto externo, sin conformar en sí mismo una fase, estaría comprendido en la segunda (que cubre, según se asume normalmente, hasta SComp). Sin embargo, no pretendemos con esta decisión particular extraer ninguna consecuencia teórica de largo alcance. La misma idea puede expresarse acogiendo otras versiones de la organización estratificada de la cláusula, con la condición de que se asuma, como es habitual, que las capas más internas (Sv) corresponden a la codificación del Aktionsart junto con la Estructura Argumental. Recientemente, una alternativa teórica, tanto a la noción de fase como a la de secuencia cartográfica de proyecciones, corresponde a la idea de dominios (Ramchand \& Svenoniuos 2014; Wiltschko 2014; Ramchand 2018), en la que se reconocen tres grandes estratos semánticamente motivados sin, necesariamente, incluir una secuencia rígida de nodos en cada nivel. Esta propuesta es similar a la que se plantea en modelos sintácticos de inspiración funcionalista (RRG, FDG), según puede apreciarse en la revisión de Narrog (2012). Parece común a distintos enfoques contemporáneos, por consiguiente, la tesis de que la cláusula se organiza en distintos niveles, de forma que el aspecto gramatical (o de punto de vista) incide sobre el aducto proporcionado por un nivel estructural más interno. Nuestra propuesta sobre la distribución de los sufijos -ncia y -nte viene a fortalecer esta concepción de la cláusula.

${ }^{4}$ En lo sucesivo, analizaremos la lectura disposicional como un tipo de aspecto, que se generaría en el nivel del aspecto genérico ('no episódico'). Nótese que la lectura disposicional parece incorporar, con todo, un valor modal ('el cuchillo corta' $\rightarrow$ 'el cuchillo puede cortar'). Al margen de si este valor es un efecto interpretativo del operador aspectual genérico, o debe formularse como una operación semántica independiente, lo que nos interesa es destacar que esta lectura comporta un valor estativo derivado (tal como sucede con los auxiliares modales del tipo poder o deber). Para una propuesta explícita sobre el valor disposicional como modal, véase Lekakou (2005); para una implementación en términos aspectuales, que es la que aquí se sigue, véase Alexiadou \& Schäfer (2010).

5 «Entrante y saliente pueden aplicarse respectivamente a quien se dispone a ocupar un cargo y a quien se dispone a abandonarlo. No se trata de títulos ni de denominaciones oficiales, sino de una forma de aclarar a qué presidente (entrante o saliente) nos estamos refiriendo en cada caso» (Fundéu RAE).

${ }^{6}$ Usamos el término eventualidad (tomado de Bach 1986) como un concepto amplio que cubre tanto estados como eventos (dinámicos). No pretendemos discutir aquí la forma exacta de representar sintácticamente la distinción entre estados y eventos. Así, pueden proponerse diferentes opciones que incluyen: (i) la sintaxis manipula solo una variable de eventualidad a la que se asigna un valor aspectual más específico en la interfaz conceptual; (ii) la sintaxis manipula tanto la variable <evento> para los eventos, como <estado> para los estados (cf. Parsons 1990); y (iii) los estados se 
definen como eventualidades por defecto siempre que Sv carece de <evento>. Para más discusión sobre esta cuestión, véanse Parsons (1990), Katz (2000), Maienborn (2005), Martin (2008), Rothmayr (2009), Horno Chéliz (2011), Roy (2013), Marín (2013), entre muchos otros. Aquí seguimos la propuesta de que los estados deben contener una variable pero esta no puede ser la misma que subyace a los predicados de evento. Por tanto, adoptamos la idea de que $V$ puede introducir bien un <evento $>$ bien un <estado $>$.

7 Pharies (2002: S.v. -ENCIA, -ANCIA, -ANZA) recoge algunos casos eventivos de -encia, -ancia y -anza que pertenecen al siglo XIII: escogencia de escoger; atrevencia (cf. atrevimiento) de atrever; mantenencia (cf. mantención) de mantener; loancia de loar; demostrancia (cf. demostración) de demostrar; vengança de vengarse.

${ }^{8}$ Siguiendo a Oltra-Massuet (1999) y Oltra-Massuet \& Arregi (2005), también Fábregas (2014), asumimos que las vocales temáticas son morfemas sin una correspondencia sintáctica o semántica directa, que se introducen en español en estructuras que ya tienen categoría gramatical con el fin de satisfacer un requisito morfológico. En nuestros derivados, la vocal temática (VT) se introduce post-sintácticamente en el componente morfofonológico e identifica la conjugación verbal. Con fines únicamente expositivos, en nuestra representación sintáctica la vocal se añade en $\mathrm{V}^{\circ}$, que proporciona categoría gramatical a la raíz.

${ }_{9}$ Por supuesto, esto no implica que los procesos derivativos no puedan alterar la morfofonología de la base (e.g. describir > descripción, construir > construcción), sino que la adjunción del siguiente proceso derivativo típicamente respeta la base que se adopta inicialmente, esté o no alterada. Así, lo que resulta raro en el par influyente/influencia es que si el último se forma a partir del primero implicaría alterar una base que ya ha sido alterada en el proceso derivativo anterior, cuando influyente se ha formado sobre influir. Agradecemos a Elena Felíu esta observación. 